\title{
Sob o Risco do Natural: Acidente e Repetição em Flagrantes de Desastres da Natureza
}

\section{Felipe da Silva Polydoro}

Doutorando no Programa de Meios e Processos Audiovisuais da Escola de Comunicações e Artes da Universidade de São Paulo (ECA/USP). É mestre em Comunicação Social pela PUCRS. E-mail: felipepolydoro@gmail.com
Resumo: Os registros anônimos em vídeo estão entre os documentos visuais preponderantes no relato e na memória de episódios recentes envolvendo desastres naturais. Vistas isoladamente, estas imagens dotam-se de um duplo regime: a objetividade documental na reprodução do fato, a subjetividade de uma câmera-olho instável que remete ao sensório. Testemunhas da irrupção de um acontecimento, trazem inscrita a singularidade do acaso, efeito potencializado pelo registro de uma ação determinada por causas naturais alheias à vontade do sujeito que filma. Pensados em conjunto, esses vídeos compõem um interminável e repetitivo banco de dados de evidências documentais sobre determinado evento.

Palavras-chave: Registro anônimo; vídeos amadores; análise de imagens.

Title: The Risk of Nature: Accident and Repetition in Recordings of Natural Disasters

Abstract: Anonymous video recordings are important visual documents in the depiction and constitution of the visual memory of recent natural disasters. Taken alone, these images acquire a dual quality: the documentary objectivity of the fact's reproduction and the sensorial subjectivity of an unstable camera-eye. Witnesses of the outbreak of a natural event, they carry within themselves the uniqueness of chance, an effect that is strengthened by the recording of an event determined by natural causes, thus beyond the control of the person behind the camera. When thought together, these videos make up an endless and repetitive database of documentary evidence regarding a particular event.

Keywords: Anonymous recording; amateur videos, analysis of image.

\section{Registro anônimo e apelo realista}

Entre os vídeos anônimos contemporâneos que registram acontecimentos de relevância histórica e jornalística, alguns dos mais vistos e compartilhados - e visualmente impactantes - são aqueles que captam fragmentos imagéticos de desastres naturais. Em diversos lugares da web, encontram-se coleções de flagrantes audiovisuais de acontecimentos tais como os tsunamis no Sudeste Asiático, em 2004, e no Japão, em 2011; a passagem de furacões nos Estados Unidos; os deslizamentos decorrentes do excesso de chuvas na Região Serrana do Rio de Janeiro, em 2011. Pode-se afirmar que os registros audiovisuais captados por anônimos, sobretudo desta figura que os meios de comunicação batizaram "cinegrafista amador", destacam-se como a peça documental preponderante na memória e nas narrativas sobre esses eventos. 
Há, nos planos estético e discursivo, consideráveis apelos em imagens amadoras que captam um fato durante sua ocorrência: um encontro da função documentalobjetiva de dar a conhecer visualmente o evento tal como ocorreu na realidade efetiva com a função testemunhal-subjetiva de reproduzir a sensação e o ponto de vista de um sujeito presente ao vivo na cena (contribuem para tal, além da perspectiva da realidade tomada a partir do olho de um sujeito, os efeitos típicos da filmagem amadora: câmera tremida, uso inábil do zoom, textura pixelada). Se, conforme Didi-Huberman (2012), toda imagem tem um regime duplo, esta imagem encontra-se potencializada em seus dois regimes: tanto em sua dimensão de documento, evidência factual, quanto na dimensão sensória, reprodução da experiência sensível. Distinguimos com alguma clareza o que aconteceu; somos como que afetados pelos referentes como se lá estivéssemos.

É claro que nem todas as captações anônimas de acontecimentos produzem os mesmos efeitos - afinal, trata-se de um objeto audiovisual já multiplicado, com variada qualidade de relevância. Daí a necessidade, para quem estuda tal tipo de imagem, de formular agrupamentos, aproximar tipos de imagens - o que faremos neste texto com alguns registros de desastres naturais.

\section{Acaso e necessidade nos flagrantes de tsunami}

${ }^{1}$ Este vídeo está disponível no endereço: http://www.youtube.com/ watch?v=5K6evRtpdAw. Visualizado em 29/09/2014.
A partir de um vídeo específico ${ }^{1}$, tentemos nos colocar no lugar do sujeito que mantém a câmera ligada diante do avanço de um tsunami. A cena em questão é parte do amplamente noticiado terremoto japonês, em março de 2011, evento pródigo em registros audiovisuais. Antes de tudo, impõem-se duas óbvias necessidades: o indivíduo precisa estar presente ao acontecimento e munido de um equipamento eletrônico com câmera. A segunda condição, o porte permanente de um celular que fotografa e filma, tornou-se algo como um procedimento necessário no processo de subjetivação ocidental contemporâneo. Se existe acaso, ele reside na primeira (e apenas na primeira) condição: o lance de dados do destino quis que aquele sujeito e seu celular presenciassem o tsunami em uma situação propícia à filmagem. Importante repetir este ponto: a onipresença de câmeras, configuração na qual a disponibilidade de um equipamento apto a documentar visualmente torna-se uma condição necessária, tende a arrefecer o efeito de surpresa e a inscrição do acaso em vídeos como o ora analisado. Toda vez que irrompe um evento de certa magnitude, pode-se concluir pela existência de registros audiovisuais do ocorrido. Se em outros tempos a disponibilidade de documentos visuais de grandes acontecimentos obedecia um princípio de raridade - há um único registro do assassinato de Kennedy - hoje vigora um princípio de abundância. E mais: se o espalhamento de câmeras funda-se na renovada estratégia do poder, agora tornado biopoder, então a incidência do acaso talvez seja apenas ilusória, uma falsificação obrada por um simulacro de jornalista.

A observação pura e simples do vídeo não esclarece o quanto o cinegrafista sabe, de início, sobre o terremoto e o tsunami. Durante quarenta e dois segundos, vê-se apenas ondas no horizonte distante e, embora soem algumas sirenes ao fundo, não se percebe a anormalidade. É claro que o espectador do Youtube, quando clica no play, já sabe-se diante do tsunami japonês de 2011, informação que consta no título da página que exibe as imagens. Mas, se nos detivermos exclusivamente no que é mostrado no filme, é só a partir do instante $0^{\prime} 42$ ", quando uma vaga atravessa a barreira de concreto, que o extraordinário começa a invadir a tela. Aos 1 '50", o zoom a enquadrar os barcos se movendo sinaliza que o acontecimento pode atingir o patamar de desastre. Aos 2'20", as ondas atravessam uma segunda barreira. Aos 2'30", a câmera se agita, aponta para o chão, o cinegrafista se move, corre até um terreno mais alto: a água já se aproxima do ponto onde ele está. Instala-se de vez a ameaça. Desde então, o cameraman é um sujeito ao mesmo tempo ameaçado e desafiador, que se arrisca em nome da filmagem. 
Até o fim, ele registrará a evolução do mar a submergir gradativamente toda a marina que é cenário do vídeo - de artefato humano, sobram apenas os barcos. No instante 8 '00, enquadra uma ponte até então oculta, com uma van parada, "atacada" pelo choque das ondas por diversos lados (impossível identificar se há alguém dentro do veículo). 0 operador move a lente: outrora distantes, os barcos foram levados pela correnteza a uma área próxima ao cinegrafista. Aos 8'25", ele sobe mais um lance de escada - uma corrida acelerada e urgente. Mira a câmera para baixo e mostra as águas invadindo o espaço que ocupava (vangloria-se de ter-se arriscado até o último instante)?

Foi a ciência da aproximação de uma onda gigante o impulso para acionar a câmera? Ou ele simplesmente gravava algo próximo ao mar quando a maré subiu e atraiu sua atenção? A impressão é de que ele liga a câmera já ciente do fenômeno natural em andamento. Neste caso, o sujeito - e não a imagem - foi surpreendido pela irrupção deste evento. Pode-se aventar, porém, que a versão a qual temos acesso está editada e existe em algum lugar um vídeo mais longo. Não sabemos, nem saberemos - e é bom salientar que essas questões acerca da psicologia do cinegrafista estão um tanto caricaturais, pois não cremos numa consciência límpida e uma intencionalidade clara por parte do sujeito que filma.

Se são as experiências de interação com o mundo externo que constroem o sujeito - e se contemporaneamente estas experiências constitutivas se dão através da mediação de dispositivos eletrônicos - o sujeito deste filme materializa-se dotado de uma relação ambígua com o poder da natureza: se deslumbra com o espetáculo natural, mas o enfrenta. Munido de seu aparato artificial, transmuta a fúria marítima em imagem numérica, apta a ser compartilhada, vista incontáveis vezes, modificada em softwares de manipulação. Haverá no ato de documentar digitalmente este acontecimento - virtualizá-lo - a utopia de exercer algum controle sobre o poderio natural? O que leva este sujeito a gravar o que vê - e arriscar-se?

Em um nível raso, sem mergulhar na complexa hermenêutica desse sujeito, o vídeo em si sinaliza para a ação de um ímpeto de registrar o fenômeno grandioso. A irrupção de um evento cujas causas são da ordem do mundo, sobre as quais o sujeito não exerce influência alguma, redunda em comandos em série: mire o celular, aperte o botão, filme, capte, compartilhe, faça circular. Na verdade, a impressão é de que há uma automatização do processo: este sujeito encontra-se programado para filmar (a constatação sobre o automatismo procedimental não brota desse exemplo específico, mas da análise sistemática de vídeos amadores que captam fatos de relevância). Perguntado, o cinegrafista seria incapaz de responder racionalmente sobre por que registrar visualmente este fato - não seria mais sensato usar o aparelho para alertar parentes e amigos?

Interpelado originalmente pelo movimento incomum do mar, este cinegrafista amador manterá a câmera ligada mesmo quando as ondas tomarem conta de quase todo o espaço diegético, ameaçando-o - o título do vídeo no Youtube anuncia: "This man risked his life to film" ${ }^{2}$. Ou seja, a vontade de documentar explicita-se não apenas na ação inaugural de acionamento da câmera, mas também na manutenção do ato por quase dez minutos, isso em condições de aparente insegurança. Dominado pela pulsão escópica, o cinegrafista parece arriscar-se até o limite.

De fato, salta aos olhos a imposição, a urgência e a atratividade visual do referente. O espetáculo de destruição descortina-se tão arrebatador e ostensivo que parece tomar conta do cinegrafista: cada estouro de onda, cada movimento abrupto dos barcos chamam o enquadramento para si. O acontecimento - suas nuances e desenrolares, suas micro-irrupções - governa a câmera. 0 tempo alongado do filme, um plano-sequência de quase dez minutos com ritmo pendendo para o lento, resulta da temporalidade do próprio fato: o mar, tal um bloco único que se avoluma, se apropria dos espaços com certa demora, diferentemente de representações de maremoto vistas no cinema, em que uma única e enorme onda, dotada da típica 
${ }^{3}$ Nesta cena do filme coreano Haeundae (Yoon Je-kyoon, 2009) disponível do Youtube, vê-se a aproximação de um tsunami cuja formação é ondular - a onda quebra já na praia: https://www. youtube.com/watch?v=k8IAgUNr6x4. Embora visualmente belo, este modo de figurar o maremoto difere consideravelmente dos registros que abundam na internet (portanto, há diferença marcante entre "representação" e "realidade").

${ }^{4} \mathrm{O}$ esquema da visão no pensamento de Lacan (1988) desafia a tradição teórica que separa, de um lado, um sujeito observador dotado de um olho fixo e, de outro, um mundo repleto de objetos a serem observados. Central nessa concepção é a noção de olhar, um ponto localizado não no sujeito, mas no mundo, que funciona como um chamariz à visão e que, por formar-se pela projeção do desejo, participa do processo de constituição do sujeito que olha - afinal, o desejo se constitui no outro, ganha existência somente quando projetado. Neste sistema, o sujeito não é o ponto de partida do fenômeno da visão, mas principalmente o ponto de chegada (talvez o mais correto é dizer que, no esquema escópico lacaniano, há uma tensão nunca resolvida entre os dois eixos, um partindo do olho do observador, o outro partindo do olhar situado no mundo; formam-se aí duas linhas que nunca se encontram, numa estrutura quiasmática, uma dinâmica que Lacan (idem) definiu como a dialética entre o olho e o olhar). 0 olhar vincula-se à pulsão escópica, ao mecanismo que projeta o desejo do sujeito em um objeto do mundo, criando uma espécie de foco visual sobre o qual se concentra o motor da pulsão. Este objeto sobre o qual o desejo é projetado ganha, na teoria lacaniana, a denominação de objeto $a$. Em síntese, o olhar é o objeto $a$ tal como este opera no mecanismo da visão.

${ }^{5} \mathrm{O}$ vídeo pode ser visto em http://www. youtube.com/watch?v=ceym2c180QM. Acessado em 29/09/2014. forma ondular, "quebra" sobre a cidade ${ }^{3}$. No entanto, não há sobras na ação, nem insistência em um enquadramento na busca de algo mais fundamental atrás ou além da imagem - nada relacionado à defesa baziniana do plano longo como abertura ao essencial. Embora lento aos olhos de uma cultura audiovisual dominada por montagens velozes, esse plano sequencia está cheio de acidentes no nível mais aparente, desenlaces que monopolizam a atenção e resolvem-se na camada mais superficial. Nota-se os apuros do operador ao tentar mostrar tudo o que ocorre em seu campo de visão - inepto, vacila no movimento de câmera.

Sendo assim, este vídeo, bem como os demais registros de tsunami, constitui-se não de um, mas de uma série de instantes decisivos. Há vários punctums (Barthes, 1989). No vídeo descrito acima, fomos especialmente afetados no instante em que a primeira onda estoura; quando o cinegrafista corre para escapar da invasão das águas; quando o cinegrafista enquadra os barcos próximos de si; no trecho em que as ondas ameaçam um veículo parado na ponte; quando o câmera pela segunda vez alcança um terreno mais alto para escapar da corrente. Ou pode-se localizar a pungência dessas imagens no próprio avanço contínuo, destrutivo, do oceano. Em suma, há algo que é da ordem do referente que nos olha de volta nestes vídeos de desastres naturais - a noção de olhar entendida aqui no sentido definido por Lacan (1988) ${ }^{4}$.

Em tese, estamos diante de fatos cuja causa encontra-se exclusivamente em contingências da natureza. Ninguém representa para a câmera, não há encenação no sentido estrito, não há intervenção humana no decorrer da cena, a não ser indiretamente: as construções artificiais que se tornam obstáculo para o mar. Não existe vislumbre de corpo humano em nenhum momento do vídeo. Vê-se, a partir de uma câmera subjetiva, o mundo em sua performance neutra, destruindo todo e qualquer ente (passa por cima do natural e do artificial). Ao homem (a este específico, mas também à espécie humana diante de força natural de tal magnitude) resta a única alternativa de filmar. Isso aparece mais evidentemente em outro vídeo ${ }^{5}$ do evento japonês, no qual a intensidade da destruição é maior. Neste, aparentemente, o cinegrafista fica sem escapatória, não há opção de fuga. Assiste, do topo de um prédio, à ruína generalizada. $O$ cenário é a beira de um rio já transbordante, mas com os arredores ainda intactos. É possível ver a avenida paralela ao rio e, do outro lado desta, um prédio com estacionamento (cheio de automóveis), seguido de uma vila de casas (além da construção sobre a qual posta-se o cinegrafista acidental). Quando o vídeo se inicia, a corrente já carrega um bolo de carros e as ondas começam a tomar conta da avenida. Ao final, praticamente toda a vila de casas estará inundada. Dezenas de construções serão devastadas e os carros vistos no início das filmagens vão desaparecer do campo de visão. Nos últimos instantes, a água se aproxima ameaçadoramente do parapeito em frente ao operador. Como o vídeo descrito antes, este também estrutura-se pelo progresso contínuo das águas - agora mais veloz e arrasador.

Sem saída e testemunha de uma devastação singular, o operador desta filmagem é um sujeito ainda mais desprotegido, ameaçado, impotente. E este protagonismo do acontecimento, cuja aleatoriedade governa todas as ações, cujo desenrolar como que "dirige" a câmera, está inscrito nessas imagens. O evento dá-se a ver, narra a si próprio, e o sujeito, encastelado, tenta desajeitadamente gravar no celular o espetáculo de destruição no qual está metido. Neste vídeo, não há nem o tom desafiador do cinegrafista descrito anteriormente. Naquele, a assunção deliberada do risco denotava ambiguidade, entre o fascínio e a provocação. O operador se movia, desfrutava de alguma liberdade de escolha na troca com os referentes (ainda que o espaço de ação fosse mínimo). Agora, não há negociação: um operador fixo restringe-se a mover a câmera entre três tipos de enquadramentos, num diâmetro de 180 graus.

Não existe neutralidade no ato de documentar e reproduzir a realidade. A própria decisão de duplicar o mundo em imagem já indica um espírito interventor e a 
filosofia do século $X X$ terminou de esclarecer que a assim chamada realidade não passa de um construto de complexa elaboração. Os variados realismos, bem como o efeito de presença que surtem, decorrem sempre de operações nos níveis estético e discursivo, cujas estratégias e cujos efeitos variam de época para época - e a disseminada estética do amadorismo desponta como um dos recursos realistas mais potentes na contemporaneidade. É o tipo de efeito que provoca este segundo vídeo analisado, portador de um discurso realista paradoxal que sintetiza a objetividade na reprodução do fato e a subjetividade de uma câmera-olho cuja movimentação e textura remetem constantemente para sua presença mediadora (e o efeito da mediação de feição amadora é o de um contato direto física e temporalmente com a realidade; sensação de uma experiência não-mediada).

\section{Real e semblante}

De indexicalidade realçada, dotados de uma crueza nas condições de captação, os flagrantes anônimos remetem ao reincidente ímpeto de registrar visualmente a coisa em si. E religar-se a uma realidade mais imediata e "autêntica", livre da membrana plástica do espetacular, é uma das marcas da cultura contemporânea, conforme diagnóstico de autores como Baudrillard (1991), Zizek (2003), Jaguaribe (2007), Feldman (2008), entre outros. Para Badiou (2007), o século XX foi dominado pela "paixão pelo real"- ou o exame contínuo da ligação, efetivamente indistinguível, entre real e semblante. "Laços que resultam do fato de o semblante ser o verdadeiro princípio de situação do real, aquilo que localiza e torna visíveis os brutais efeitos da contingência do real" (Badiou, 2007, p. 81).

Fenômeno amplo, essa investigação em torno da fronteira entre realidade eaparência se expressou, nas artes e em manifestações midiáticas, tanto na intensificação de estratégias miméticas quanto na recusa da representação para realçar a materialidade do suporte. A proliferação dos registros amadores - e sua apropriação como artifício estético realista no cinema e em outros produtos audiovisuais - representam uma continuidade deste movimento. Em outro trabalho (Polydoro, 2013), analisamos o renovado efeito de real em vídeos que captam o instante de irrupção de um acontecimento imprevisto alheio à intenção original do sujeito que filma (caso do filme amador que documentou a morte de John Kennedy e do flagrante do choque do primeiro avião no ataque terrorista ao World Trade Center).

Tais imagens não são uma inovação do paradigma digital. O século XX produziu uma boa porção de flagrantes audiovisuais. Conforme Bruno (2006, s.p.):

Sabe-se que a novidade não reside no uso do flagrante capturado por câmeras amadoras, já há muito comum no jornalismo. A "novidade" consistena intensificação desta prática e no "efeito de real" que tais imagens hoje produzem.

Nas imagens que analisamos (Polydoro, op. cit.), o fato registrado produz uma espécie de rasgo na imagem, ao intrometer-se numa cena que decorria dentro da normalidade. Algumas dessas imagens não apenas dão a ver os pormenores de um acontecimento relevante - relevância de ordem midiática atribuída sempre $a$ posteriori - mas oferecem o vislumbre de um real mais íntimo e profundo, cuja característica, segundo Lacan (1988), é exatamente o de irromperinesperadamente e, nesta irrupção, mostrar de si apenas um vestígio. É deste real, no sentido lacaniano, que fala Badiou (2007): o não-simbolizável, o traumático que assombra mas ao mesmo tempo sustenta as ordens do simbólico e do imaginário.

${ }^{6} \mathrm{O}$ vídeo está disponível neste endereço: http://www.youtube.com/ watch?v=ihN1qYVhka4. Acessado em 29/09/2014.
Nos dois vídeos de desastres naturais analisados acima, o acontecimento não rasga a imagem de maneira brusca e inesperada. Em ambos os casos, nota-se que o operador aciona a câmera em resposta ao fato já em andamento. Embora se possa perceber vestígios da eclosão do fortuito - cuja faísca é anterior ao princípio da filmagem - o efeito é diferente, por exemplo, do de um terceiro ${ }^{6}$ registro de 


\begin{abstract}
${ }^{7}$ Há situações em que os internautas se valem dos espaços de comentários para corrigir informações erradas a respeito dos vídeos - ou, no mínimo, postam dúvidas ligadas à veracidade, reforçando o princípio de incerteza que é marca estatutária dessas imagens. A cena de um filme coreano para a qual remete a nota 3 foi postada como um registro "real" do tsunami japonês de 2011, informação corrigida na caixa de comentários.
\end{abstract}

${ }^{8}$ Conceito de Dominique Maingueneau (2004) que engloba o conjunto total de elementos presentes no ato de enunciação que influenciam o processo de significação de um enunciado. Ao deparar-se com um enunciado, o público irá valer-se de todos os elementos discursivos existentes na cena de enunciação para (ainda que inconscientemente) situar o discurso e compreender o significado. No caso do Youtube, a cena de enunciação abarca o vídeo exibido, mas também as demais informações constantes na página (o título e a descrição do vídeo, os dados do autor, os vídeos relacionados listados no canto, a publicidade que entra antes e durante a exibição) além da estrutura de "janelas" dos computadores e celulares, que possibilitam ao usuário acessar virtualmente qualquer site à procura de informações extra. tsunami, agora do episódio ocorrido no Sudeste Asiático, em 2004 (o título do vídeo no Youtube informa que a cena se passa na Malásia). O pai (ou o que parece ser um pai) grava os filhos brincando na praia, até ser abruptamente surpreendido pela súbita progressão da maré. Não se veem danos materiais e físicos relevantes: todos correm e gritam, mas parecem escapar ilesos. A extensão dos estragos é muito inferior aos dos vistos nos vídeos já mencionados, mas, diferentemente daqueles, este vídeo carrega o arrepio do acidental, um efeito de surpresa. Aqui a coincidência não é deduzida a partir de uma remissão a um tempo anterior enxergamos o acaso atuando em direto, ao vivo. Vemos e ouvimos o susto dos personagens atingidos pelas ondas.

No entanto, uma questão é se este efeito de surpresa não se acha parcialmente - ou integralmente - esvaziado pela forma como tais imagens circulam e são exibidas, dúvida que se aplica a esse vídeo mas também aos registros amadores de maneira geral. Há um lapso entre a indeterminação essencial dessas imagens na sua constituição bruta original e o contexto de enunciação (no Youtube ou em redes sociais como o Facebook, onde aparecem acompanhadas de textos e outros enunciados esclarecedores sobre o acontecimento em questão, isso para um público conectado e informado). Os títulos dos vídeos, por exemplo, costumam antecipar os elementos e ações mais atrativos ao internauta - seguem a mesma lógica da manchete jornalística, voltada a revelar de saída o mais relevante e a angariar a atenção pela vontade de saber mais e não jogar com o suspense sobre o ocorrido. Além disso, as imagens do Youtube costumam vir acompanhadas de textos e comentários reveladores sobre o conteúdo e com informações adicionais a respeito dos eventos filmados ${ }^{7}$.

Contraditoriamente, isolados, vídeos como os analisados neste artigo encontramse, desde o início de sua exibição, contaminados por um princípio de incerteza. Voltemos ao primeiro dos objetos descritos aqui. Para a maioria dos espectadores que assistem ao vídeo no Youtube (o filme contava pouco mais de três milhões de visualizações em fevereiro de 2014), o local exato é incerto, o cinegrafista é desconhecido (jamais aparece, quase não fala), não há segurança sobre se o vídeo tal como gravado ao vivo começa e termina da forma como está exibido. Trata-se de imagens sem origem e sem autoria - num sentido bastante literal.

Um espectador que se deparasse apenas com o vídeo, sem dados adicionais, talvez não conseguisse enquadrar o acontecimento no tempo e no espaço. Carente de uma "cena de enunciação", este espectador visualizaria perceptos em um estágio pré-significação, um real em um nível pré-discursivo. Porém, não existe acesso a esta camada de primeiridade, ao documento ainda cru, desprovido de reflexividade. Ainda que esses objetos audiovisuais em si mesmos reproduzam a precariedade e a crueza da captação, o contexto de enunciação pende para o excesso (de palavras, imagens, vídeos relacionados ao mesmo acontecimento ou a acontecimentos semelhantes, além da disponibilidade de ferramentas hipermidiáticas que permitem novas buscas sobre o mesmo tema). A confusão e a incerteza que acompanham essas imagens, uma certa instabilidade na confecção de sentido, decorrem não da pobreza sígnica, mas do excesso de máscaras - e aqui se percebe o quanto o contexto de enunciação contradiz o efeito de real alcançado pelo vídeo em si mesmo, particularizado por simular uma reprodução direta e imediata com o concreto do mundo.

No contexto midiático contemporâneo, os flagrantes de eventos devem ser pensados não apenas enquanto mônadas isoladas, mas também na relação com outros registros do mesmo episódio. A construção dos acontecimentos não se dá exclusivamente por meio de uma ou outra peça narrativa, mas por uma miríade de testemunhos, relatos, versões (reportagens jornalísticas em todos os suportes midiáticos, filmagens da lavra de amadores e de câmeras de segurança, entre outros enunciados factuais). Se nos detivermos apenas ao que está disponível no 
${ }^{9} \mathrm{O}$ endereço é http://www. tsunami2004.net. Acessado em 29/09/2014.

Youtube, o grande relato audiovisual do tsunami japonês abarca uma infinidade de vídeos amadores, tele-reportagens, montagens de registros anônimos feitos por internautas também anônimos (espécies de pastiches de reportagens jornalísticas). A soma de todos esses documentos - cuja quantidade é incalculável - redunda em uma coleção vastíssima de evidências visuais deste acontecimento de importância histórica. Conforme Manovich (2001), a ontologia do ciberespaço remete a uma estrutura de banco de dados. Portanto, a forma narrativa própria a espaços computacionais não obedece à consagrada armadura linear e sequencial, em que cada ação estabelece uma relação lógico-causal com a anterior, mas apresenta-se com a estrutura não-hierarquizada, interativa e hipermidiática do banco de dados. Acontecimentos midiático-históricos de grande magnitude originam sites que são, ao mesmo tempo, arquivo, memória e narrativas em potencial. O site Tsunami $2004^{9}$, por exemplo, reúne informações e registros do episódio (muitos no formato de vídeo).

Um banco de dados repleto de registros factuais ligados a determinado evento estabelece uma relação com a realidade caracterizada pela abundância e o excesso. Em vez de um flagrante único, singular, dotado de uma aura de autenticidade uma imagem, um punctum, um instante decisivo - temos um regime do visível que multiplica os testemunhos: profusão de versões, de ângulos, de pontos de vista. Um real registrado por todos os lados, escaneado em todas as dimensões, decalcado em todas as nuances. A documentação abundante do acontecimento que irrompe possibilita a repetida observação do vislumbre do real (em si mesmo não-simbolizável, efêmero em sua aparição). E o semblante é o lugar de localização do real. "O abrupto do real opera apenas em ficções, montagens, máscaras" (BADIOU, 2007, p. 83).

De certa forma, a multiplicação dos registros e sua disponibilidade nos espaços virtuais incitam a repetição. A estrutura de banco de dados e a coleção de testemunhos visuais da efemeridade do real remetem ao realismo traumático descrito por Hal Foster (2014) - agora em outro patamar discursivo, não mais no terreno da arte. Neste texto, Foster (op. cit.) analisa a série de pinturas "Morte e Desastre" de Andy Warhol, composta por imagens de acidentes, desastres e outras figuras que remetem à morte e à violência. São pinturas feitas a partir de fotografias, algumas delas registros fotojornalísticos de acidentes de automóvel. Como é do feitio do movimento pop dentro do qual Warhol se notabilizou, os quadros repetem a mesma fotografia várias vezes. Na obra "Green Car Crash", o instantâneo de um carro em chamas, virado do avesso, aparece seis vezes. Para Foster (op. cit., p. 129), a pungência desse realismo não se encontra no horror da imagem, mas na reiteração da cena violenta. $O$ abrupto da violência captada na fotografia encontra-se diminuído, frente ao poder da repetição desse instante traumático. É uma arte lida com a urgência de um real profundo com a reiteração e não com a remissão ao referente enquanto acontecido.

\footnotetext{
O punctum em Warhol está menos nos detalhes do que nos lampejos repetitivos da imagem. Esses lampejos servem como equivalente visual de nossos encontros faltosos com o real, do mesmo modo que a imagem fora de registro ou uma lavada na cor. "O que se repete", escreve Lacan, "é sempre algo que se produz [...] como por acaso". É como esses lampejos: parecem acidentais, mas também parecem repetitivos, automáticos, até tecnológicos (FOSTER, op. cit., p. 129).
}

O mesmo nesses vídeos de flagrantes que pipocam no Youtube: acidentais porém repetitivos. Trazem a inscrição do acaso e do fortuito, mas solicitam a repetição: o mesmo vídeo visto diversas vezes; o mesmo acontecimento visto por diversos ângulos. Estimulam uma compulsão pelo ver e rever, como percebe qualquer pessoa que já gastou longo tempo assistindo a vídeos no Youtube. 0 automatismo, portanto, domina tanto o cinegrafista quanto o espectador. 


\section{Referências Bibliográficas}

BADIOU, Alain. O século. Aparecida: Ideias \& Letras, 2007.

BARTHES, Roland. A câmara clara. Rio de Janeiro: Nova Fronteira, 1989.

BAZIN, André. O cinema: ensaios. São Paulo: Brasiliense, 1991.

BAUDRILLARD, Jean. Simulacros e simulação. Lisboa: Relógio D’Água, 1991.

BRUNO, Fernanda. Estética do flagrante: controle e prazer nos dispositivos de vigilância contemporâneos. In: Revista Cinética, Rio de Janeiro, 2006. Disponível em: http://www.revistacinetica.com.br/cep/fernanda_bruno.htm

COMOLLI, Jean. Ver e Poder. Belo Horizonte: UFMG, 2008.

DIDI-HUBERMANN, Georges. Imagens apesar de tudo. Lisboa: KKYM, 2012.

FELDMAN, Ilana. O apelo realista. In: Revista Famecos, n. 36, agosto de 2008.

FOSTER, Hal. O retorno do real. São Paulo: Cosac Naify, 2014.

JAGUARIBE, Beatriz. O choque do real: estética, mídia e cultura. Rio de Janeiro: Rocco, 2007.

LACAN, Jacques. O Seminário 11: os quatro conceitos fundamentais da psicanálise. Rio de Janeiro: Jorge Zahar, 1988.

MAINGUENEAU, Dominique. Análise de textos de comunicação. São Paulo: Cortez, 2004.

MANOVICH, Lev. The language of the new media. Cambridge: MIT Press, 2001

POLYDORO, Felipe. A ubiquidade das câmeras e a intrusão do real na imagem. In: Anais do XXII Encontro Anual da Compos; junho de 2013; Salvador (BA), 2013.

ZIZEK, Slavoj. Bem-vindo ao deserto do real! São Paulo: Boitempo, 2003. 